\title{
The effect of fractures on gas injection in Hailar oilfield
}

\author{
Changhao Wang ${ }^{1}$ D $\cdot$ Shibin $\mathrm{Li}^{1}$
}

Received: 3 February 2018 / Accepted: 10 May 2018 / Published online: 12 June 2018

(c) The Author(s) 2018

\begin{abstract}
The channeling of $\mathrm{CO}_{2}$ gas is affected by the development of reservoir fractures. In order to improve the gas injection effect, the finite element numerical analysis software Comsol Multiphysics combined with the fluid-solid coupling theory was used to establish the three-dimensional geological model of the Hailar Bei 14 block, and the geostress of the study block was inverted. According to the failure criterion of rocks, the natural fractures of the block are predicted, and the distribution characteristics of artificial fractures are obtained by combining the fracturing situation and fracturing time sequence. Based on the simulation of the pressure field and flow field distribution of the Bei 14, the main effect of the fractures on the gas injection is revealed. The reason of the gas channeling in the Bei 14-X51-59 well is analyzed, which provides an important basis for the formulation of the $\mathrm{CO}_{2}$ flooding scheme.
\end{abstract}

Keywords $\mathrm{CO}_{2}$ flooding $\cdot$ Fracture $\cdot$ Gas channeling $\cdot$ Finite element numerical simulation $\cdot$ Fluid-solid coupling

\section{Introduction}

At present, there are many outstanding problems in improving the recovery of low permeability reservoirs, and gas injection (including $\mathrm{CO}_{2}$ injection) is one of the most promising methods to solve this problem (Yu et al. 2015; Zhao et al. 2016; Yuncong et al. 2014). However, the application of $\mathrm{CO}_{2}$ flooding is accompanied by many problems. Among them, the gas channeling is the most important factor affecting recovery (Mungan 1992; Amin et al. 2010). Through a large number of pilot tests and laboratory experiments, the main causes of gas channeling in different types of reservoirs and different development stages are different, but all are affected by the development of fractures (Hao et al. 2016; Chen et al. 2015). Therefore, the evaluation and the prediction of reservoir fractures are the main factors, which control the effectiveness of channeling $\mathrm{CO}_{2}$ gas flooding, which provides an important basis for the formulation of $\mathrm{CO}_{2}$ flooding schemes (Cho and Lee 2017).

The prediction of fractures is mainly based on logging and seismic information identification methods. These methods

Changhao Wang

wangchanghao8888@163.com

1 School of Petroleum Engineering, Northeast Petroleum University, High-tech Development Zone, 99 Xuefu Street, Daqing 163318, Heilongjiang, China are limited by conditions, such as difficult data collection and unpredictable fracture directions. Therefore, different researchers used different methods to construct fractured porous media. Unneberg (1974) and Zakirov et al. (1991) identified the annular space formed between the core and the cylindrical vessel in which the core was placed as a fracture, establishing an experimental method. Thompson and Mungan (1969) used a thin blade to cut the entire vertical core, creating a fracture in the core. Then, the effect of fracture density on the gas channeling was analyzed. Thomas et al. (1983) established a three-dimensional numerical model of a fractured reservoir and applied it to gas injection development. However, this model was not able to fully reflect the mechanism of gas flooding. The above studies have a certain understanding of the influence of fractures on gas injection, but they have not been able to analyze the distribution of natural fractures and artificial fractures, which cannot determine the $\mathrm{CO}_{2}$ migration situation in a specific block.

The Hailar Bei 14 block is located in the Sudeerte structural belt in the Baier oilfield, where the fault density is high and the artificial fractures are widely distributed. The oil production of the well group was increased rapidly after the gas injection in this block, which resulted in a significant decrease in the moisture content, and the effect of gas injection was obvious. However, the oil production was decreasing with the progress of gas injection, and the effect was deteriorated. From the contribution of the single well, the proportion of crude output in

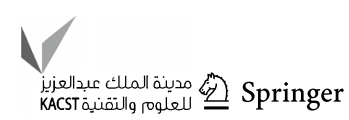


the wells of multi-directional response is higher than that in unidirectional response. The wells of unidirectional response, such as Bei 14-X51-59, $\mathrm{CO}_{2}$ enter the production wells quickly after gas injection, so that the well is gas channeling rapidly and the stable phase of the crude output is short. Therefore, from the geostress field and induced stress field, this paper analyzes the development characteristics of fractures in Bei 14 block and its influence on gas injection.

\section{Fluid-solid coupling}

During the mining process in the oil and gas field, the stress field will change with time, and the original reservoir pressure equilibrium state will be destroyed, which will lead to deformation and affect the reservoir's physical properties. In addition, changes in the physical properties of the reservoir will also affect the flow of its internal fluid (Guyer and Kim 2015; Liang et al. 2001). Therefore, this paper establishes a geological model of the Hailar Bei 14 block under fluid-solid coupling conditions.

\section{Fluid control equation}

The fluid flow must follow the law of conservation of matter (Lehmann and Ackerer 1998). The conservation law for the general compressible Newtonian flow is described by the following control equations.

Mass conservation equation:

$\frac{\partial \rho_{\mathrm{f}}}{\partial t}+\nabla \cdot\left(\rho_{\mathrm{f}} v\right)=0$

Momentum conservation equation:

$\frac{\partial \rho_{\mathrm{f}} v}{\partial t}+\nabla \cdot\left(\rho_{\mathrm{f}} v v-\tau_{\mathrm{f}}\right)=f_{\mathrm{f}}$,

where $t$ is time, $f_{\mathrm{f}}$ is the volume force vector, $\rho_{\mathrm{f}}$ is the fluid density, $v$ is the fluid velocity vector, $\tau_{\mathrm{f}}$ is the shear force tensor.

$\tau_{\mathrm{f}}=(-p+\mu \nabla \cdot v) I+2 \mu e$,

where $p$ is fluid pressure, $\mu$ is dynamic viscosity, $e$ is speed tensor, $e=\frac{1}{2}\left(\nabla v+\nabla v^{T}\right)$.

\section{Solid control equation}

The conservation equation for the solid part can be derived from Newton's second law:

$\rho_{\mathrm{s}} d_{\mathrm{s}}=\nabla \cdot \sigma_{\mathrm{s}}+f_{\mathrm{s}}$.

where $\rho_{\mathrm{s}}$ is the solid density, $\sigma_{\mathrm{s}}$ is the Cauchy stress tensor, $f_{\mathrm{s}}$ is the volume force vector, $d_{\mathrm{s}}$ is the acceleration vector of solid.

\section{Fluid-solid coupling equation}

Similarly, fluid-solid coupling follows the most basic conservation principle. Therefore, the stress $(\tau)$, displacement $(d)$, heat flow $(q)$ and temperature $(T)$ between the fluid and solid are equal and conservative at the interface of the fluid-solid coupling. The basic control equations used in the fluid-solid coupling analysis can be obtained by combining the above control equations ( $\mathrm{Ng}$ et al. 2009).

The three-dimensional stress inversion model of the Hailar Bei 14 block is established by the Separation Solution of fluid-solid coupling, and the influence of the fractures on the gas injection is analyzed.

\section{Three-dimensional geological model and geostress field inversion}

Based on the comprehensive analysis of tectonic evolution, 3D seismic data interpretation and real drilling data, the three-dimensional geostress field simulation study is carried out combined with fluid-solid coupling model. The block geological structure model is established according to the reservoir top structure diagram, the seismic time profile, the elevation of the seismic reflection layer, the actual drilling data and the stratigraphic data (Maerten et al. 2006; Pei et al. 2014). The following is an example of the II oil group in Bei 14 block and the main rock mechanic parameters and physical parameters are shown in Table 1. The results of geostress inversion are shown in Fig. 1.

It can be seen from the simulation results that the stress state of the study area is the compressive stress. In the middle area of the major faulting, the maximum horizontal principal stress is concentrated in the range 31-43 $\mathrm{MPa}$, and the minimum horizontal principal stress is distributed between 30 and $37 \mathrm{MPa}$, which represents the general level of geostress.

Table 1 The related parameters of Hailar Bei 14 block model

\begin{tabular}{lll}
\hline $\begin{array}{l}\text { Rock mechanics } \\
\text { parameters and physical } \\
\text { parameters }\end{array}$ & $\begin{array}{l}\text { The II oil group } \\
\text { in Bei 14 block }\end{array}$ & $\begin{array}{l}\text { The faulting of the II } \\
\text { oil group in Bei 14 } \\
\text { block }\end{array}$ \\
\hline $\begin{array}{lll}\text { Elastic modulus (MPa) } \\
\text { Poisson's ratio }\end{array}$ & 9657.8 & 3863.1 \\
$\begin{array}{l}\text { Density }\left(\mathrm{kg} / \mathrm{m}^{3}\right) \\
\begin{array}{l}\text { High permeability/low } \\
\text { permeability }(\mathrm{mD})\end{array}\end{array}$ & 0.21 & 0.227 \\
\hline
\end{tabular}




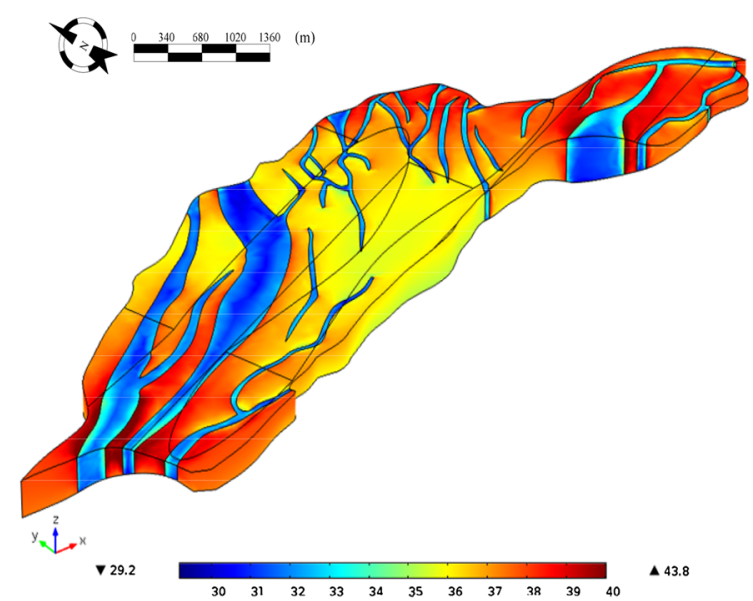

(a) Maximum horizontal principal stress

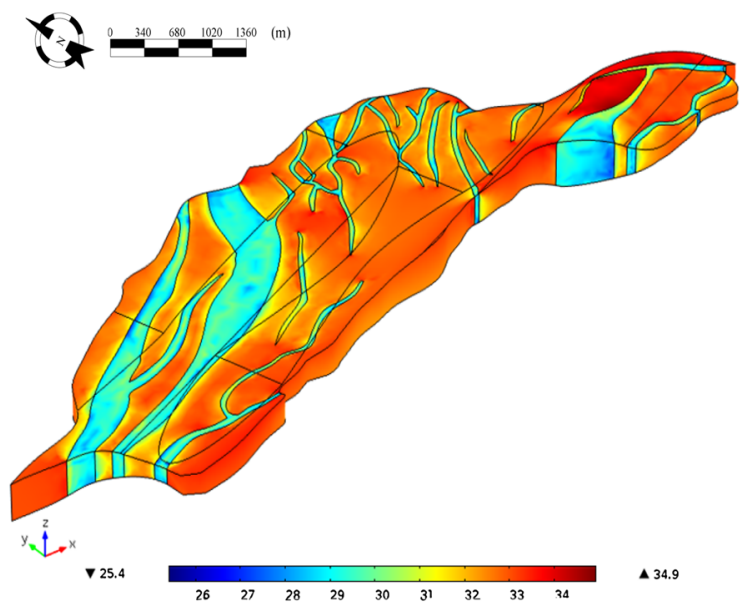

(b) Minimum horizontal principal stress

Fig. 1 The geostress inversion of Hailar Bei 14 block II oil group

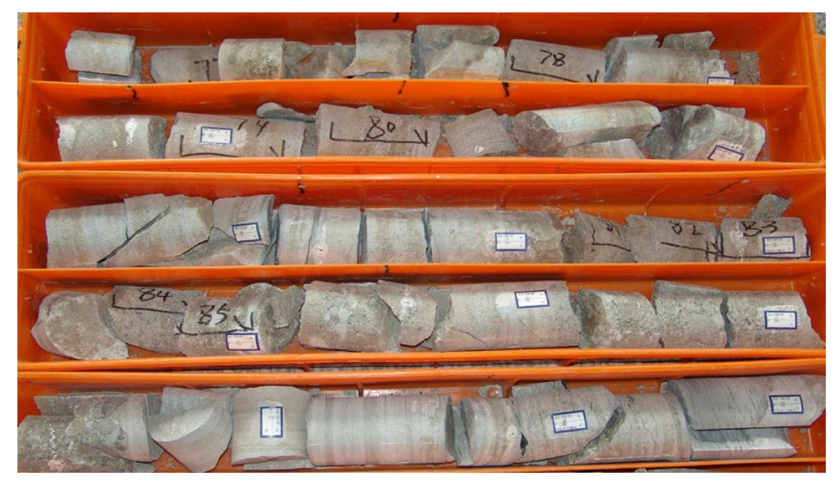

Fig. 2 Bei 14-X56-54 well core photos

\section{The development characteristics and distribution prediction of fractures}

According to the results of the three-dimensional geologic model and the inversion of the geostress field of the Hailar Bei 14 block, the distribution of the natural fractures of the block is predicted by referring to the failure criterion (Rahimi and Nygaard 2015). In addition, the distribution characteristics of the artificial fractures are determined.

\section{The distribution of natural fractures in Hailar Bei 14 block}

The lithology of the Bei 14-X56-54 well is mostly the sandstone of reverse rhythm in the II oil group. As shown in Fig. 2, the natural fractures in the block are not developed according to the rock of continuous coring. Since the formation of fractures needs to meet the rock failure criterion, the criterion is substituted into the geological model of the Hailar Bei 14 block to judge the development of the natural fractures in the whole block.

\section{Griffith's fracture criterion}

The Griffith fracture criterion (Boggio and Vingsbo 1976) is mainly applied when the extensional fracture is formed by tensile stress. The mathematical expression is:

when $\sigma_{1}+3 \sigma_{3}>0$,

$\sigma_{\mathrm{t}}=\frac{\left(\sigma_{1}-\sigma_{2}\right)^{2}+\left(\sigma_{2}-\sigma_{3}\right)^{2}+\left(\sigma_{1}-\sigma_{3}\right)^{2}}{24\left(\sigma_{1}+\sigma_{2}+\sigma_{3}\right)}$.

when $\sigma_{1}+3 \sigma_{3}<0$,

$\sigma_{\mathrm{t}}=\sigma_{1}$,

where $\sigma_{1}, \sigma_{2}, \sigma_{3}$ are the three principal factors of stress (compressive stress is positive). $\sigma_{\mathrm{t}}$ is the tensile stress on the broken surface.

$T$ is defined as the extensional fracture index and $T=\left|\frac{\sigma_{\mathrm{t}}}{\left[\sigma_{\mathrm{t}}\right]}\right|$, where, $\left[\sigma_{\mathrm{t}}\right]$ is the tensile strength of rock. The index $T$ is used to describe the degree of the development of the extensional fracture in the formation. The higher the $T$, the better the degree of development of extensional fracture.

\section{Mohr-Coulomb failure criterion}

The Mohr-Coulomb failure criterion (Labuz and Zang 2012) is mainly applied when the shear fracture is formed by shear stress.

$\tau=C+\sigma_{\mathrm{n}} \tan \varphi$, 
where $\tau$ is the shear strength on shear plane, $C$ is cohesion, $\varphi$ is angle of internal friction, $\sigma_{\mathrm{n}}$ is normal stress on the shear plane.

$\sigma_{\mathrm{n}}=\frac{\sigma_{1}+\sigma_{3}}{2}+\frac{\sigma_{1}-\sigma_{3}}{2} \cos 2 \alpha$,

where $\sin 2 \alpha=\frac{1}{\sqrt{1+\mu^{2}}}, \cos 2 \alpha=\frac{-\mu}{\sqrt{1+\mu^{2}}}$.

$F$ is defined as the shear fracture index and $F=\left|\frac{\tau}{[\tau]}\right|$, where, $[\tau]$ is the shear strength of rock. The index $F$ is used to describe the degree of the development of the shear fracture in the formation. The higher the $F$, the better the degree of development of shear fracture. The fracture index is evaluated as shown in Table 2.

According to the distribution of stress field and seepage field, combined with the failure criterion of rock and the evaluation, the development of extensional fracture and shear fracture in II group is shown in Fig. 3. It can be seen that the natural fracture is relatively developed near the faulting, and it is undeveloped in the other areas.

\section{The distribution characteristics of artificial fractures}

Through a large number of field practices, it has been found that the fracturing operation and the dynamic changes in the injection-production will induce deflection of the stress

Table 2 Evaluation of fracture index

\begin{tabular}{llll}
\hline $\begin{array}{l}\text { The degree of } \\
\text { fracture develop- } \\
\text { ment }\end{array}$ & $\begin{array}{l}\text { The fracture- } \\
\text { developed areas }\end{array}$ & $\begin{array}{l}\text { The relatively } \\
\text { fracture-devel- } \\
\text { oped areas }\end{array}$ & $\begin{array}{l}\text { The fracture- } \\
\text { undeveloped } \\
\text { areas }\end{array}$ \\
\hline $\begin{array}{l}\text { Fracture index } \\
T / F\end{array}$ & $>0.5$ & $0.3-0.5$ & $<0.3$ \\
\hline
\end{tabular}

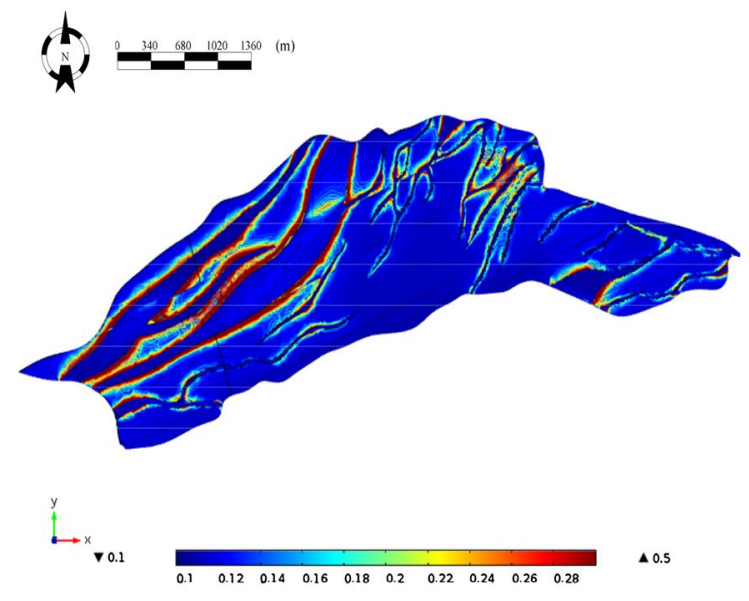

(a) extensional fracture field (Gao et al. 2016), resulting in the turn of post-fracturing fractures. Since many wells in the Bei 14 block have undergone multiple fracturing, knowledge of the stress field before each fracturing of each well is the basis for studying the trend of fractures. The original ground stress field in block Bei 14 was measured by laboratory tests. The original geostress field in the Bei 14 block was measured jointly by paleomagnetism, velocity anisotropy, differential strain and acoustic emission experiments. The vertical stress, maximum horizontal principal stress, minimum horizontal principal stress, direction and error analysis results for each group of specimens are shown in Table 3 .

The direction of the ground stress in Block 14 is $\mathrm{N} 46.0^{\circ} \mathrm{E} \pm 1^{\circ}$. The maximum horizontal principal stress gradient is approximately $2.26 \mathrm{MPa} / 100 \mathrm{~m}$. The minimum horizontal principal stress gradient is about $1.93 \mathrm{MPa} / 100 \mathrm{~m}$. The error deviation is in the range $0.47-4.67 \%$.

According to the fracturing situation and fracturing time sequence of the well pattern, the distribution characteristics of the artificial fractures can be obtained (Ye et al. 2015). The forecasting method is as follows (Fig. 4).

According to the above method, the distribution characteristics of the artificial fractures of II oil group in Hailar Bei 14 block are shown in Fig. 5. A total of 29 wells underwent fracturing operations between 2006 and 2015, including two wells that were multiple fracturing. From the prediction results, it can be seen that the fractured well Bei 14-X56-54 first produced a fracture along the direction of the original geostress. As a result of the existence of artificial fractures and the initiation of injection-production, an induced stress field was generated and the direction of the geostress in this area is turned. Based on the distribution of the maximum horizontal principal stress at that time, the fracture directions of other wells after the fracturing operation were sequentially

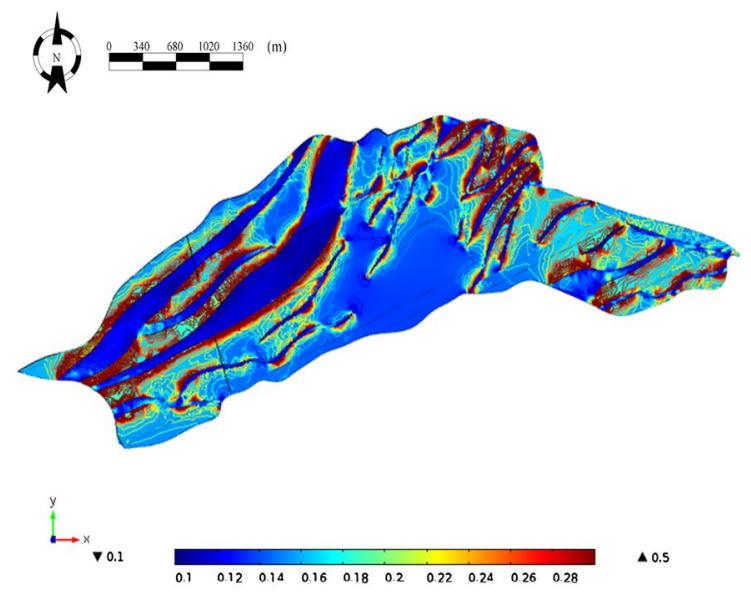

(b) shear fracture

Fig. 3 The development situation of natural fracture of II oil group 
Table 3 Ground stress test results in block 14 of Hailarbei

\begin{tabular}{|c|c|c|c|c|c|c|}
\hline Core & Well number & Test category & $\begin{array}{l}\text { Vertical } \\
\text { stress }(\mathrm{MPa})\end{array}$ & $\begin{array}{l}\text { Maximum horizontal } \\
\text { principal stress }(\mathrm{MPa})\end{array}$ & $\begin{array}{l}\text { Minimum horizontal } \\
\text { principal stress (MPa) }\end{array}$ & $\begin{array}{l}\text { Maximum horizontal } \\
\text { principal stress direction } \\
\left(^{\circ}\right)\end{array}$ \\
\hline \multirow[t]{5}{*}{ BDY-1 } & \multirow[t]{5}{*}{ Bei 14-X56-54 } & Velocity anisotropy & - & - & - & $\mathrm{N} 43.8^{\circ} \mathrm{E}$ \\
\hline & & Acoustic emission & 37.61 & 42.75 & 32.50 & $\mathrm{~N} 45.2^{\circ} \mathrm{E}$ \\
\hline & & Differential strain & 37.61 & 40.61 & 34.72 & $\mathrm{~N} 44.5^{\circ} \mathrm{E}$ \\
\hline & & Error $(\%)$ & 0.00 & 3.63 & 4.67 & 1.67 \\
\hline & & Average & 37.61 & 41.68 & 33.61 & $\mathrm{~N} 44.5^{\circ} \mathrm{E}$ \\
\hline \multirow[t]{5}{*}{ BDY-2 } & \multirow[t]{5}{*}{ Bei 14-X54-50 } & Velocity anisotropy & - & - & - & $\mathrm{N} 45.6^{\circ} \mathrm{E}$ \\
\hline & & Acoustic emission & 35.58 & 37.60 & 31.84 & $\mathrm{~N} 46.4^{\circ} \mathrm{E}$ \\
\hline & & Differential strain & 35.58 & 37.85 & 32.25 & $\mathrm{~N} 47.7^{\circ} \mathrm{E}$ \\
\hline & & Error $(\%)$ & 0.00 & 0.47 & 0.90 & 2.11 \\
\hline & & Average & 35.58 & 37.73 & 32.05 & $\mathrm{~N} 46.5^{\circ} \mathrm{E}$ \\
\hline \multirow[t]{5}{*}{ BDY-3 } & \multirow[t]{5}{*}{ De $120-175$} & Velocity anisotropy & - & - & - & $\mathrm{N} 46.7^{\circ} \mathrm{E}$ \\
\hline & & Acoustic emission & 36.24 & 41.40 & 34.60 & $\mathrm{~N} 47.7^{\circ} \mathrm{E}$ \\
\hline & & Differential strain & 36.24 & 39.24 & 33.24 & $\mathrm{~N} 45.9^{\circ} \mathrm{E}$ \\
\hline & & Error $(\%)$ & 0.00 & 3.79 & 2.84 & 1.12 \\
\hline & & Average & 36.24 & 40.32 & 33.92 & $\mathrm{~N} 46.8^{\circ} \mathrm{E}$ \\
\hline
\end{tabular}

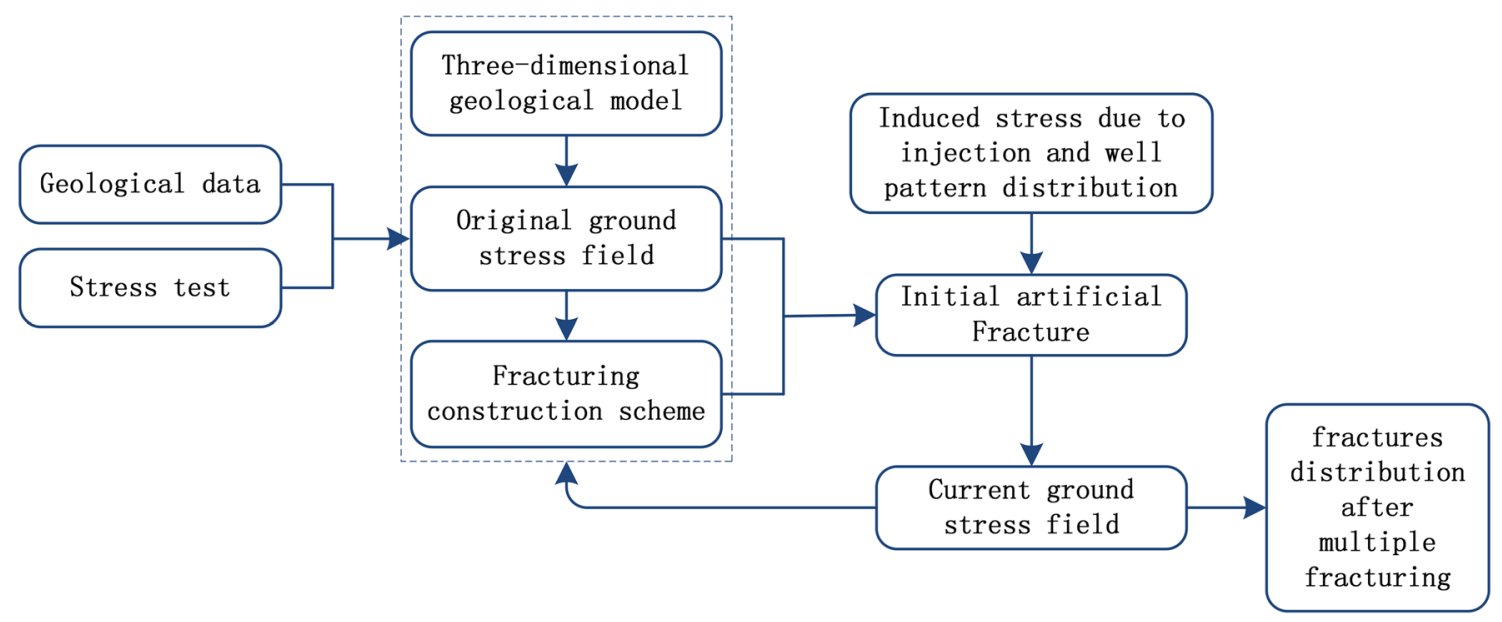

Fig. 4 Artificial fractures prediction method

obtained. Therefore, the artificial fractures in this area extend in different directions.

\section{The analysis on the influence of fractures on gas injection}

\section{The influence law of fractures on gas injection}

The fractures are critical both the impact of oil flow passage on capacity and channeling-path on $\mathrm{CO}_{2}$ advance suddenly in low-permeability reservoirs (Zhou et al. 2017;
Bertin et al. 1998). In this paper, the pressure field and the flow field of the $\mathrm{CO}_{2}$ test area in the Bei 14 block are analyzed, and the distribution map is obtained.

As shown in Fig. 6a, Bei 14-X48-53 is the gas injection well. As the well is fractured, the range of influence after gas injection becomes larger. From the distribution of the streamline in the figure, $\mathrm{CO}_{2}$ is transported from the different locations of the fractures to the surrounding production wells, so that the surrounding wells are gas channeling quickly. As shown in Fig. 6b, Bei 14-X70-66 is the production well. Due to the presence of fractures in the well, the $\mathrm{CO}_{2}$ injected into the surrounding gas injection wells can 
Fig. 5 The artificial fracture distribution characteristics of II oil group

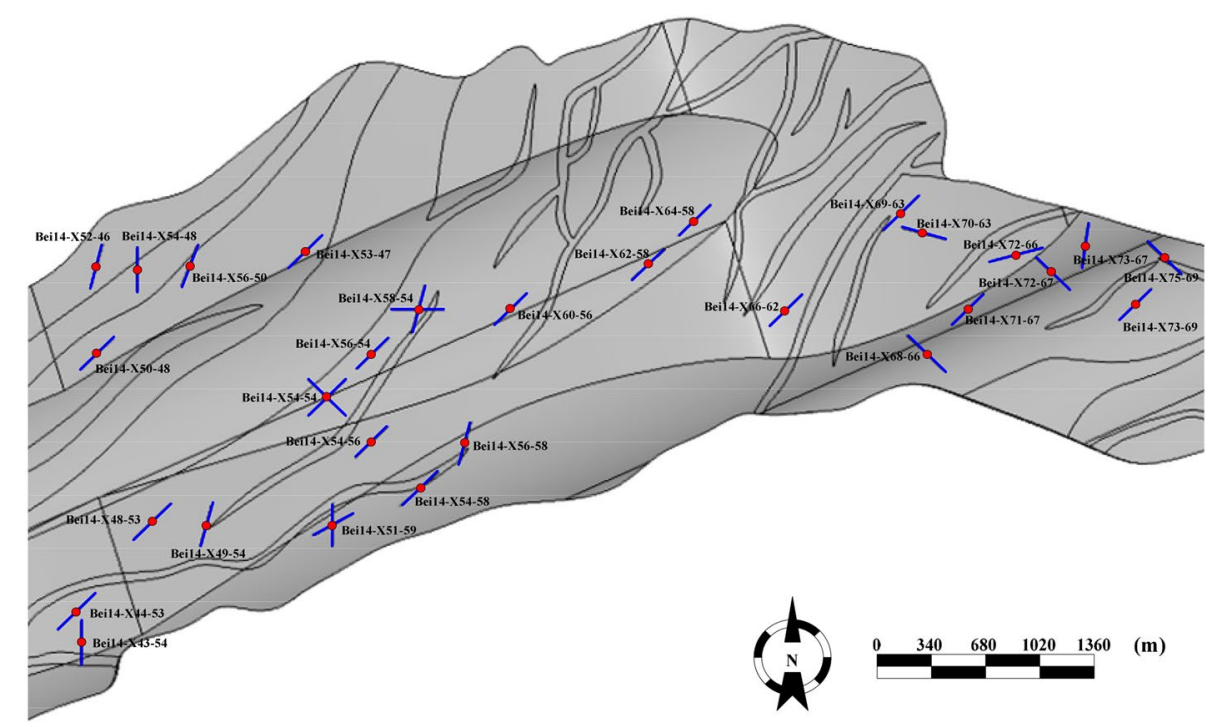

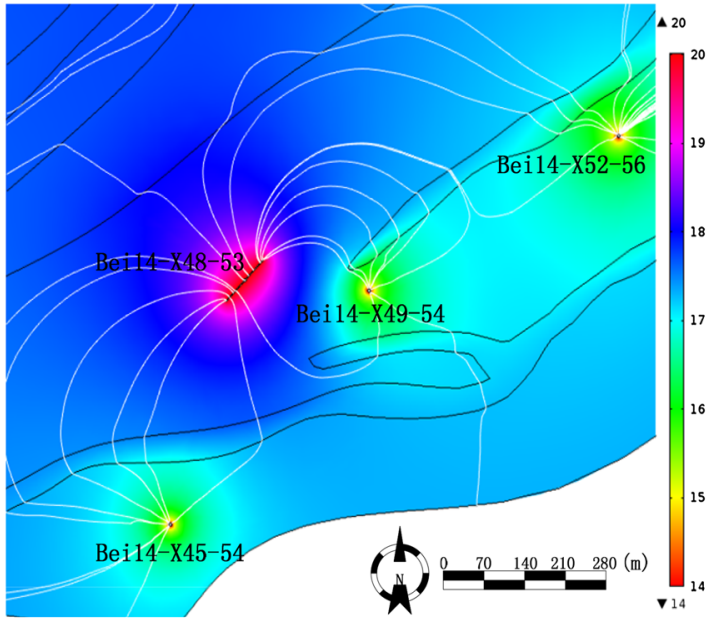

(a) The streamlines near the gas injection wells

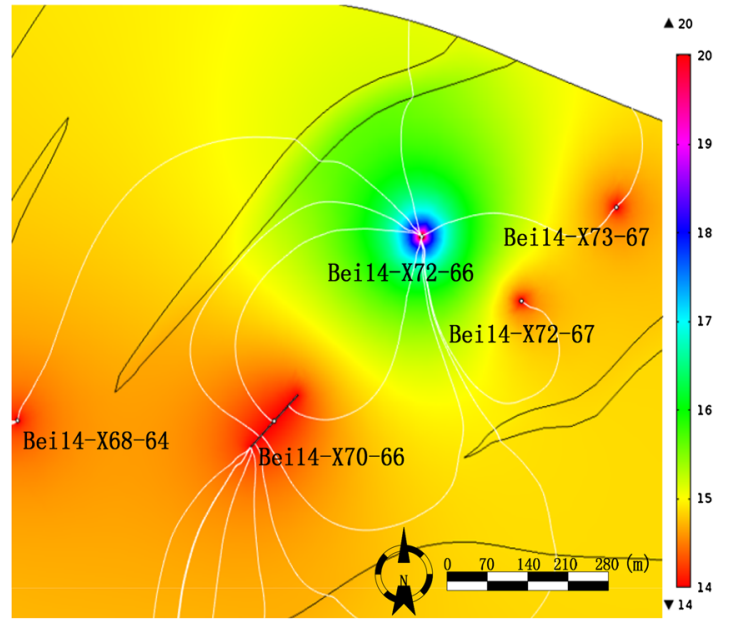

(b) The streamlines near the producing wells

Fig. 6 The distribution of flow field and pressure field near the fracture

first communicate with the fractures of Bei 14-X70-66, so that it is gas channeling quickly. It can be seen that the fractures are the preferred channels for $\mathrm{CO}_{2}$ viscous fingering and advance suddenly, so the oil wells in the direction of fractures development are gas channeling preferentially.

\section{Analysis on the causes of gas channeling of Bei 14-X51-59 well}

There are nine gas injection wells in the Hailar Bei 14 block. According to the field test data, Bei 14-X51-59 well has been gas channeling. Combined with the distribution of natural fractures and artificial fractures, the cause of the gas channeling is analyzed specifically.
It can be seen from Fig. 7 that there is only one gas injection well Bei 14-X54-58 near the 14-X51-59 well. The linear distance between the two wells located near the faulting in Bei 14 block, is about $184 \mathrm{~m}$. The Bei 14-X51-59 well was fractured twice in 2010 and 2012, respectively. At present, the Bei 14-X51-59 well was found to be $\mathrm{CO}_{2}$ gas channeling, but the Bei 14-X52-58 which is located in the middle of the two wells is not abnormal.

According to the distribution of natural fractures and artificial fractures, it is known that the Bei 14-X51-59 and the Bei 14-X54-58 have artificial fractures in the II oil group and they are located in the relatively developed areas of the natural fractures, so the two wells form a joint aisle. 


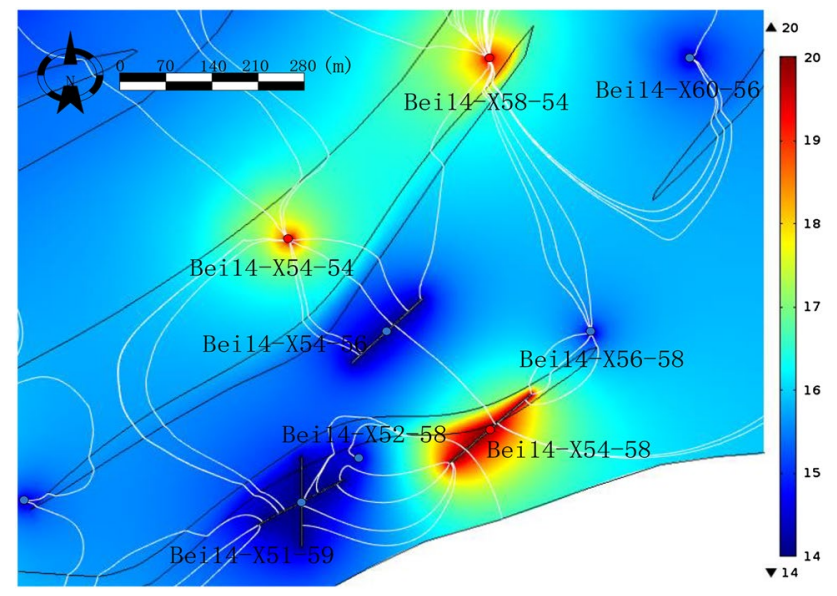

Fig. 7 Bei 14-X51-59 near the well pattern

According to the Griffith criterion, the direction of artificial fracturing generally develops along the direction of maximum stress (Sumigawa et al. 2017; Yin et al. 2015). The initial fracture direction and the secondary steering direction of fracturing may coincide with the direction of maximum principal stress. In addition, the distance between the two wells is short, and the natural fractures near the faulting are developed. Therefore, a well-connected fracture channel is formed between the Bei 14-X51-59 well and the gas injection well Bei 14-X54-58, and thus the $\mathrm{CO}_{2}$ reaches the production well quickly along the connected channel. The Bei 14-X52-58, which is closer to the gas injection well, has no artificial fractures. From the flow field distribution in Fig. 7, it can be seen that the $\mathrm{CO}_{2}$ migration channel between the gas injection well and the Bei 14-X51-59 is more than that of the Bei 14-X52-58 resulting in faster migration. These also illustrate the role of fractures in the main effect of gas channeling.

\section{Conclusion}

1. The natural fractures of II oil group are relatively developed near the faulting in Hailar Bei 14 block, and the others are underdeveloped areas.

2. When there are fractures in the gas injection well, $\mathrm{CO}_{2}$ is transported from the different locations of the fractures to the surrounding production wells. When there is a fracture in the production well, the $\mathrm{CO}_{2}$ injected from the surrounding gas injection wells first communicates with the fractures of the well, leading to the production wells in the direction of fractures development are gas channeling preferentially.

3. Fractures are the main factors that affect the gas channeling of an oil well. Due to the combined action of natural fractures and artificial fractures, a well-connected channel will be formed between the gas injection wells and the production wells, so that the production wells will be gas channeling quickly.

Open Access This article is distributed under the terms of the Creative Commons Attribution 4.0 International License (http://creativeco mmons.org/licenses/by/4.0/), which permits unrestricted use, distribution, and reproduction in any medium, provided you give appropriate credit to the original author(s) and the source, provide a link to the Creative Commons license, and indicate if changes were made.

\section{References}

Amin M, Jeelani OA, Mansouri HA (2010) Gas log monitoringchallenges and uncertainties in gas injection pilot in carbonate reservoir-a case study in UAE. J Crit Care 25(4):659.e9

Bertin HJ, Apaydin OG, Castanier LM et al (1998) Foam flow in heterogeneous porous media: effect of crossflow. SPE J 4(2):75-82

Boggio JV, Vingsbo O (1976) Application of the Griffith criterion to fracture of boron fibres. J Mater Sci 11(12):2242-2246

Chen SC, Cheng N, Hu S (2015) Simulations of primary and secondary gas penetration for a gas-assisted injection-molded thin part with gas channel. J Appl Polym Sci 67(9):1553-1564

Gao Q, Cheng Y, Fathi E et al (2016) Analysis of stress-field variations expected on subsurface faults and discontinuities in the vicinity of hydraulic fracturing. SPE Reserv Eval Eng 19(1):54-69

Guyer RA, Kim HA (2015) Nonlinear elasticity and hysteresis: fluidsolid coupling in porous media. Phys Rev E 91(4):57-80

Hao H, Hou J, Zhao F et al (2016) Gas channeling control during $\mathrm{CO}_{2}$, immiscible flooding in 3D radial flow model with complex fractures and heterogeneity. J Pet Sci Eng 146:890-901

Kim TH, Cho J, Lee KS (2017) Evaluation of $\mathrm{CO}_{2}$ injection in shale gas reservoirs with multi-component transport and geomechanical effects. Appl Energy 190:1195-1206

Labuz JF, Zang A (2012) Mohr-Coulomb failure criterion. Rock Mech Rock Eng 45(6):975-979

Lehmann F, Ackerer P (1998) Comparison of iterative methods for improved solutions of the fluid flow equation in partially saturated porous media. Transp Porous Media 31(3):275-292

Liang B, Sun KM, Xue Q (2001) The research of fluid-solid coupling in the ground engineering. J Tech Univ (Nat Sci Ed) 2:129-134

Maerten L, Gillespie P, Daniel JM (2006) Three-dimensional geomechanical modeling for constraint of subseismic fault simulation. AAPG Bull 90(9):1337-1358

Mungan N (1992) Carbon dioxide flooding as an enhanced oil recovery process. J Can Pet Technol 31(9):13-14

$\mathrm{Ng}$ YT, Min C, Gibou F (2009) An efficient fluid-solid coupling algorithm for single-phase flows. J Comput Phys 228(23):8807-8829

Pei Q, Haibo LI, Dong Y et al (2014) Study on numerical simulation of geostress field affected by slope gradient of river valleys. J Sichuan Univ 46:98-104

Rahimi R, Nygaard R (2015) Comparison of rock failure criteria in predicting borehole shear failure. Int J Rock Mech Min Sci 79:29-40

Sumigawa T, Shimada T, Tanaka S et al (2017) Griffith criterion for nanoscale stress singularity in brittle silicon. ACS Nano 11(6):6271-6276

Thomas LK, Dixon TN, Pierson RG (1983) Fractured reservoir simulation. Soc Petrol Eng J 23(1):42-54 
Thompson JL, Mungan N (1969) A laboratory study of gravity drainage in fractured systems under miscible conditions. Soc Petrol Eng J 9(9):247-254

Unneberg A (1974) Recovery of oil from fractured reservoirs by gas displacement. Texas A\&M University, College Station

Ye Z, Liu HH, Jiang Q et al (2015) Two-phase flow properties of a horizontal fracture: the effect of aperture distribution. Adv Water Resour 76:43-54

Yin H, Qi HJ, Fan F et al (2015) Griffith criterion for brittle fracture in graphene. Nano Lett 15(3):1918-1924

$\mathrm{Yu}$ W, Lashgari $\mathrm{HR}$, Wu K et al (2015) $\mathrm{CO}_{2}$ injection for enhanced oil recovery in Bakken tight oil reservoirs. Fuel 159:354-363

Yuncong G, Mifu Z, Jianbo W et al (2014) Performance and gas breakthrough during $\mathrm{CO}_{2}$ immiscible flooding in ultra-low permeability reservoirs. Pet Explor Dev 41(1):88-95

Zakirov SN, Shandrygin AN, Segin TN (1991) Miscible displacement of fluids within fractured porous reservoirs. In: Proceedings of the 1991 SPE annual technical conference and exhibition, 6 October-9 October 1991, Sigma. Society of Petroleum Engineers of AIME, pp 583-592

Zhao X, Rui Z, Liao X (2016) Case studies on the $\mathrm{CO}_{2}$ storage and EOR in heterogeneous, highly water-saturated, and extra-low permeability Chinese reservoirs. J Nat Gas Sci Eng 29:275-283

Zhou Q, Oldenburg CM, Spangler LH et al (2017) Approximate solutions for diffusive fracture-matrix transfer: application to storage of dissolved $\mathrm{CO}_{2}$ in fractured rocks. Water Resour Res 53(2):1746-1762

Publisher's Note Springer Nature remains neutral with regard to jurisdictional claims in published maps and institutional affiliations. 